\title{
FINITE LOCALLY RESONANT METAFOUNDATIONS FOR THE SEISMIC PROTECTION OF FUEL STORAGE TANKS
}

\author{
Francesco Basone $^{1,2}$, Moritz Wenzel ${ }^{2}$, Oreste S. Bursi ${ }^{2}$, Marinella Fossetti ${ }^{1}$ \\ ${ }^{1}$ Engineering and Architecture Faculty, University of Enna "Kore", Viale delle Olimpiadi, 94100 Enna, Italy \\ ${ }^{2}$ Department of Civil, Environmental and Mechanical Engineering, University of Trento, Via Mesiano 77, 38123 \\ Trento, Italy
}

Correspondence: Oreste S. Bursi, Department of Civil, Environmental and Mechanical Engineering, University of Trento, Trento, Italy. Email: oreste.bursi@unitn.it

This paper introduces a novel seismic isolation system based on metamaterial concepts for the reduction of ground motion-induced vibrations in fuel storage tanks. In recent years, the advance of seismic metamaterials has led to various new concepts for the attenuation of seismic waves. Of particular interest for the present work is the concept of locally resonant materials, which are able to attenuate seismic waves at wavelengths much greater than the dimensions of their unit cells. Based on this concept, we propose a so-called Metafoundation, which is able to shield fuel storage tanks from earthquakes. To crystallize the ideas, the Metafoundation is designed according to the Italian standards with excessive conservatism and optimized under the consideration of its interaction with both superstructure (tank) and ground. To acoomplish this, we developed two optimization procedures that are able to compute the response of the coupled foundation-tank system subjected to site-specific ground motion spectra. They are carried out in the frequency domain and both the optimal damping and frequency parameters of the metafoundation embedded resonators are evaluated. As case studies for the superstructure, we consider one slender and one broad tank characterized by different geometries and eigenproperties. Furthermore, the expected site-specific ground motion is taken into account with filtered Gaussian white noise processes modeled with a modified Kanai-Tajimi filter. Both the effectiveness of the optimization procedures and the resulting systems are evaluated through time history analyses with two sets of natural accelerograms corresponding to operating basis and safe shutdown earthquakes, respectively.

\section{KEYWORDS}

Metamaterials, Metafoundation, Multiple tuned mass damper (MTMD), Optimization procedure, Fuel storage tanks, Frequency domain analysis.

\section{INTRODUCTION}

\subsection{Background and motivations}

Natural hazards such as earthquakes can interact with critical infrastructures and cause so-called NaTech ${ }^{1}$ events (natural technological events). They can have serious consequences on both community and environment and, therefore, need to be treated with care. One example of such an event is the loss of containment (LoC) of fuel storage tanks, pipelines or other components of petrochemical plants and nuclear power plants. LoC events of such critical infrastructures need to be avoided at the highest priority, as past NaTech disasters have displayed their potential in causing substantial damage to the community and the environment. ${ }^{2}$

Fuel storage tanks in petrochemical plants need to be regarded as high risk structures, due to their fragility to earthquakes and their potential for cascading effects ${ }^{3}$. Their low impulsive frequencies can fall within the excitation frequencies of earthquakes and significant effort is required to isolate them against seismic vibrations.

In order to avoid LoC events from occurring during an earthquake, various strategies have been proposed in the field of seismic engineering. The most common solutions use lead-rubber bearings ${ }^{4}$ or spherical bearing devices ${ }^{5}$. In this work, we investigate a new type of seismic isolation based on a metamaterial concept that may offer an alternative to classical seismic isolators. Although the performance of classical isolators on superstructures has been studied in depth $^{6-7}$, they require two strong floors, exert a very high stiffness against the vertical component of an earthquake and seem to be ineffective for large structures subjected to rocking ${ }^{8}$. As a result, we propose an isolation system that does not require the use of additional strong floors or specialized devices. 
In recent years, periodic materials have received growing interest due to their ability to attenuate waves in certain frequency ranges. ${ }^{9}$ In principle, there are two types of periodic materials currently investigated for seismic engineering use: phononic crystals (PCs) and locally resonant acoustic metamaterials (LRAMs). Although both are able to create a stop band to forbid elastic wave propagation within a selected frequency band, for the attenuation of low frequency vibrations, LRAMs are better suited than PCs. This is due to their capability to exhibit low frequency band gaps that can be endowed with unit cells much smaller than the wavelength of the desired frequency region. This particular property has opened an innovative direction to reduce earthquake-induced vibrations. ${ }^{10-12}$ At the outset, two types of applications have been proposed based on this phenomenon: (i) foundations with embedded resonators ${ }^{13-16}$ capable of attenuating seismic waves effects, and: (ii) barriers that are able to redirect surface waves back into the ground ${ }^{17-20}$.

More precisely, Cheng et al. ${ }^{14}$ studied a periodic foundation composed of a reinforced concrete matrix and steel masses that are connected to the matrix with rubber layers. They demonstrated the effectiveness of their isolation system for a large set of ground motions and applied it to a nuclear power plant. However, the feedback of the superstructure and the subsequent effects on the effectiveness of the foundation have been neglected. Another highly innovative approach has been proposed by Casablanca et al. ${ }^{21}$ who studied a foundation composed of concrete plates with embedded cylindrical steel resonators. Although the efficiency of the foundation was proven with experimental tests for harmonic excitations, no considerations were made on the coupling foundation system-superstructure or the effects that expected seismic records could entail on system functionality. Furthermore, the foundation was not designed for gravity and/or seismic load combinations. In order to display the effects of the coupling between foundation and superstructure, La Salandra et al. ${ }^{16}$ investigated a periodic foundation for the isolation of fuel storage tanks in the frequency domain. They found a significant shift in the desired frequency range for the band gap and, therefore, highlighted the importance of this feedback effect. On the other hand, they did not optimize their foundation to the coupled system or considered sets of seismic records for the evaluation of the foundation effectiveness in a realistic scenario.

Following up on the most recent developments, a proper foundation must take into account both the feedback of the superstructure and the frequency content of the expected earthquake. Moreover, to ensure the feasibility of a design, the structure needs to be conform to current seismic standards. In order to set a design that can comply with all the aforementioned constraints, we investigated two different types of optimization procedures. These procedures are carried out in the frequency domain and rely on the principal of tuned mass dampers (TMDs), which represent popular passive response control devices tuned to oscillate out of phase with the primary system. ${ }^{22-24}$ It is generally recognized, indeed, that TMDs are not generally effective at reducing seismic responses, due to the fact that earthquakes include a wide frequency spectrum and often entails large vibrations for higher modes. ${ }^{25}$ As a solution, multiple tuned mass dampers (MTMD) have been proposed. Thus, it has been shown that MTMDs, with multiple different eigenproperties, can reduce the effects that ground motions entail on buildings. ${ }^{26-29}$ For these more complex systems, various optimization procedures have been established. ${ }^{30-33}$

In contrast to classical MTMD systems, the resonators of the proposed design are located below the structure instead of in correspondence with the governing modes. This needs to be taken into account by the optimization procedures. More precisely, the procedures are characterized by two different optimization parameters that are studied and compared herein: i) the maximum absolute acceleration of the impulsive mode of a tank; ii) the dissipated energy of the resonators compared to the total amount of dissipated energy. The optimization of non-conventional TMDs towards the dissipated energy is a procedure introduced by Reggio and De Angelis ${ }^{34}$ and has been adapted to the proposed design. Finally, we validate the system with time history analyses (THAs) and highlight the advantage in terms of base shear reduction when compared to a traditional foundation.

\subsection{Scope}

Along those lines, the following issues are explored hereinafter: (i) a foundation design based on the concept of metamaterials compliant with common construction standards, i.e. the Italian structural code ${ }^{35}$; (ii) the effect of the foundation flexibility on its dynamic performance; (iii) an optimization procedure that takes the feedback of a superstructure and the relevant earthquake frequency content into account.

More precisely, the elastic design of the foundation is carried out considering a response spectrum provided by the Italian code for an active seismic site located in Priolo Gargallo, Sicily, Italy. Once the principal dimensions are fixed, a set of ground motions that correspond to the uniform hazard spectrum (UHS) specified for the site, can be chosen. Then, an average power spectral density (PSD) of these accelerograms is evaluated and fitted with a modified KanaiTajimi filter. In detail, we use a Kanai-Tajimi filter modified by Clough and Penzien (KTCP-filter) and investigate three typical soil types and the above-mentioned fitted "soil type". With the results of these initial calculations, the optimization procedures can be employed to set the optimal values for frequency and damping ratio of the 
metafoundation resonators. As a result, the structure is modelled as a whole and investigated on its effectiveness. This is done with THAs of the coupled optimized foundation-tank systems subjected to the previously chosen seismic records.

The remainder of the paper is organized as follows. Firstly, the description of fuel storage tanks and the evaluation of the seismic activity of the construction site is presented in Section 2. Section 3 introduces considerations on the uncoupled metamaterial-based system and negativity concepts. Both modeling and design of the foundation-tank coupled system are presented in Section 4. Moreover, Section 5 provides optimization procedures for the evaluation of the optimal parameters of resonators. In addition, both evaluation and comparison of the coupled systems subjected to ground motions are given in Section 6. Finally, we draw conclusions and present future developments in Section 7.

\section{DESCRIPTION OF THE FOUNDATION-TANK COUPLED SYSTEM}

Steel columns with hollow steel sections and concrete slabs that define the unit cells compose the foundation. In each unit cell there is a concrete mass that is linked to the steel-concrete composite structure. In order to provide high and controllable damping values as required by the optimization process, see Section 4 , these links can be realized with wire ropes ${ }^{36}$ as sketched in Figure 4a. Moreover, to allow for the displacement of resonators, a gap of $200 \mathrm{~mm}$ between columns and concrete masses, i.e. resonators, was considered. Both the isometric and plan view of the coupled foundation-tank system are illustrated in Figure 1. In particular, the superstructure corresponds to a slender fuel storage steel tank.
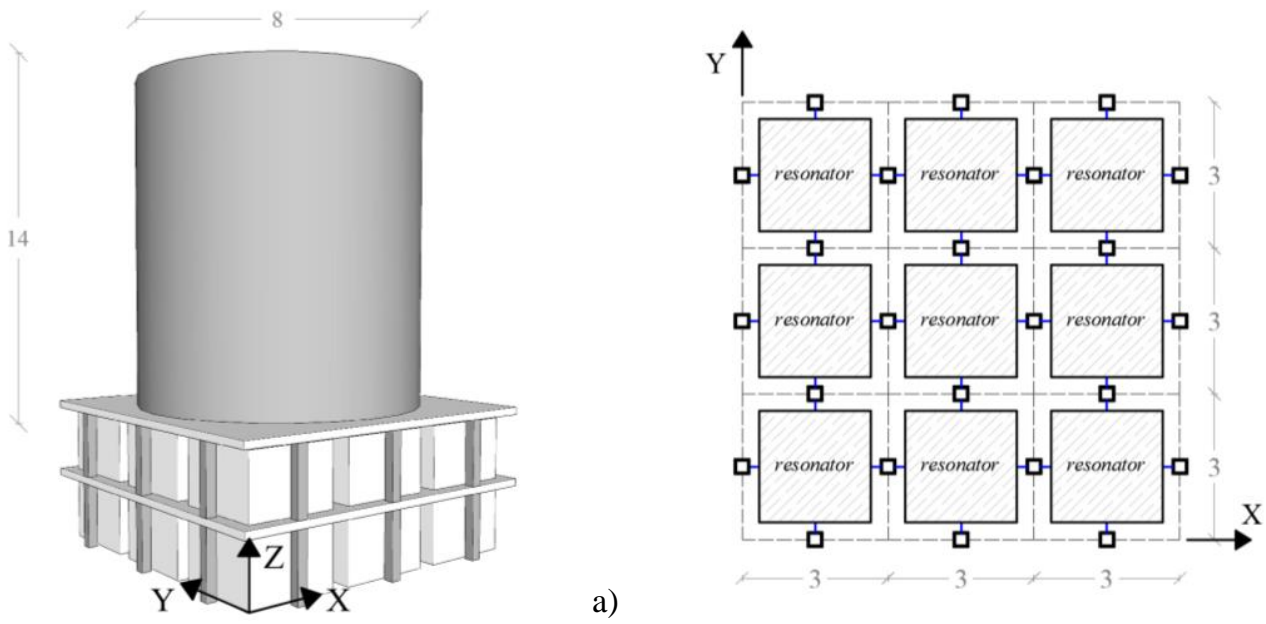

a)

b)

Figure 1 Foundation-slender tank coupled system: a) isometric view with steel columns; b) plan view. Dimensions in $\mathbf{m}$.

\subsection{Fuel storage tank modeling}

The hydrodynamic response of a tank-liquid system is mainly characterised by two different contributions, called impulsive and convective component, respectively. If the tank walls are assumed to be rigid, the impulsive component represents the portion of liquid that moves synchronously with the tank walls. Conversely, the liquid that moves with a long-period sloshing motion in the upper portion of the tank is represented by the convective component. Since there are significant differences in their natural periods, they can be considered uncoupled. ${ }^{37}$ A simplified procedure for modelling storage tanks with flexible walls has been proposed by Malhotra et al. ${ }^{37}$, who reduced the tank response to the contribution of two main modes in a plane, through coefficients dependent on tank parameters. In this respect, Figure 2 shows the sketch of a fuel storage tank and its equivalent 2D lumped mass model.

The two SDoFs that simulate both the impulsive and convective modes are connected to a rigid frame that includes the tank wall mass. Accordingly ${ }^{37}$, the vibration periods $\mathrm{T}_{i}$ and $\mathrm{T}_{\mathrm{c}}$ and the relevant modal masses $\mathrm{m}_{i}$ and $\mathrm{m}_{c}$ can be evaluated as,

$$
T_{i}=C_{i} H \sqrt{\frac{\rho R}{E t}}, \quad T_{c}=C_{c} \sqrt{R}
$$


where $\mathrm{E}, \rho$ and $\mathrm{m}_{l}$ denote the Young modulus of the tank wall, the material density and the total mass of the liquid, respectively; $\mathrm{H}$ and $\mathrm{R}$ define the liquid height and tank radius, respectively; $t$ is the equivalent uniform thickness of the tank wall while $\mathrm{C}_{i}, \mathrm{C}_{c}, \gamma_{i}$ and $\gamma_{c}$ are the parameters that depend on the tank slenderness. This procedure considers also the remaining mass $m_{s}$ lumped to the bottom plate of the tank.

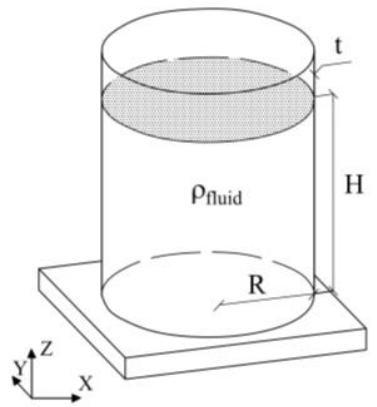

a)

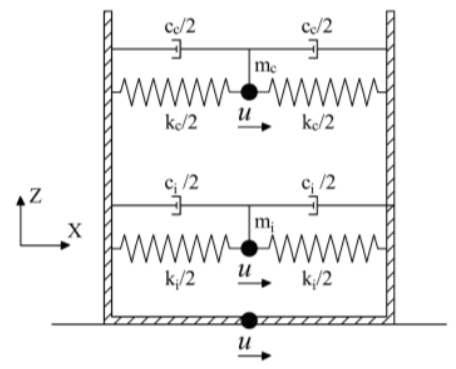

b)

Figure 2 Fuel storage tank: a) isometric view; b) 2D modeling with two SDoFs for the impulsive and convective mode (after Malhotra et al. ${ }^{37}$ ).

Clearly, the impulsive mode is strongly dependent on the fluid level and the stiffness of the tank walls, while the convective mode is mainly influenced by the tank radius. The stiffness values of the equivalent linear springs $k_{i}$ and $k_{c}$ can be calibrated to match the tank properties as follows,

$k_{i}=m_{i}\left(\frac{2 \pi}{T_{i}}\right)^{2}, \quad k_{c}=m_{c}\left(\frac{2 \pi}{T_{c}}\right)^{2}$

Since the impulsive mode contains the highest participant mass, especially for slender tanks, the Metafoundation has been designed for the attenuation of the impulsive mode.

In this paper two types of tanks characterized by different height $\mathrm{H}$, radius $\mathrm{R}$ and tank wall thickness $t$ have been considered. Table 1 shows the main geometrical characteristics of the two considered tanks and the resulting frequencies for their impulsive and convective modes.

Table 1 Main characteristics of broad and slender tanks.

\begin{tabular}{ccc}
\hline & $\begin{array}{c}\text { Broad } \\
\text { Tank }\end{array}$ & $\begin{array}{c}\text { Slender } \\
\text { Tank }\end{array}$ \\
\hline Diameter [m] & 48.0 & 8.0 \\
Wall thickness [mm] & 20.0 & 6.0 \\
Tank Height [m] & 15.6 & 14.0 \\
Maximum liquid height [m] & 15.0 & 12.0 \\
Convective frequency [Hz] & 0.34 & 0.12 \\
Impulsive frequency [Hz] & 6.85 & 3.95 \\
\hline
\end{tabular}

\subsection{Modeling of the coupled foundation-tank system}

The two SDoFs that simulate the tank-liquid system along the $\mathrm{X}$ direction, see Figure 1, are defined in the previous subsection and depicted in Figure 3. Moreover, the Metafoundation modeling is carried out condensing both masses and stiffnesses of the resonators of each layer to one stack of unit cells. This dynamic condensation in both $\mathrm{X}$ and $\mathrm{Y}$ direction is exact, since all the resonators are endowed with the same mass $m_{2, i}$ and stiffness $k_{2, i}$ and operate in parallel in each layer. The same condensation is also applied to masses $m_{l, i}$ and stiffnesses $k_{l, i}$ of the unit cells, which are assumed to behave as a shear-type system. Therefore, being interested in the motion along, let's say the X direction, each layer consists of only 2 DoFs: one for the resonators and one for the cells, respectively. 
A sketch of the system and the corresponding lumped mass model is shown in Figure 3a for the single-layer foundation; and in Figure $3 \mathrm{~b}$ for the two-layered foundation. From a model viewpoint, the resonators are attached to the upper layer via springs and are assumed to slide on a friction less surface.

Tank and foundation

Dynamic model

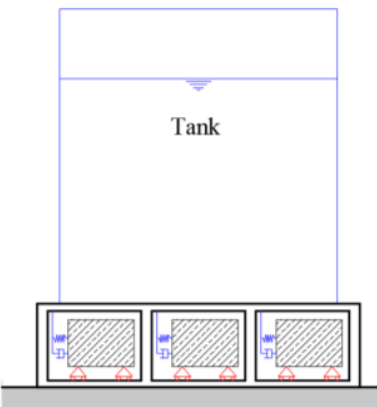

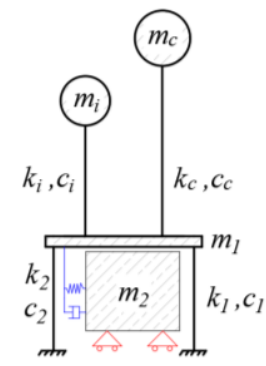

Tank and foundation

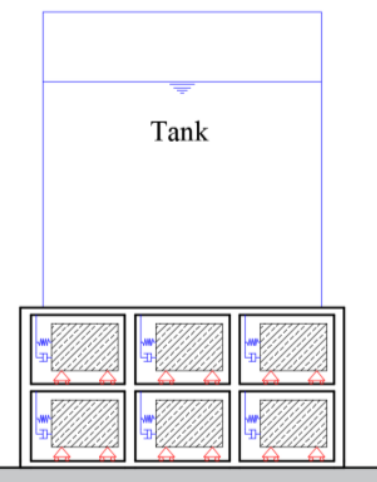

Dynamic model

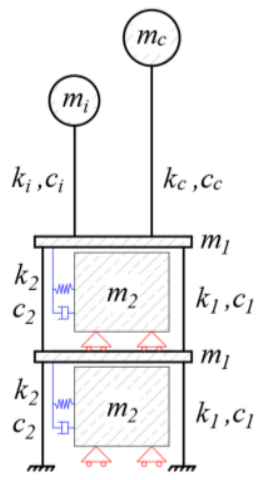

a)

Figure 3 Tank-foundation coupled systems: a) one-layer case; b) two-layer case.

Hence, the system of the equations of motion (EOM) can be defined as follows,

$$
\mathbf{M} \ddot{\mathbf{u}}(t)+\mathbf{C} \mathbf{u}(t)+\mathbf{K} \mathbf{u}(t)=-\mathbf{M} \boldsymbol{\tau} \ddot{u}_{g}(t)
$$

where $\mathbf{M}, \mathbf{C}$ and $\mathbf{K}$ are the mass, damping and stiffness matrices, respectively, while $\ddot{\mathbf{u}}(t), \dot{\mathbf{u}}(t)$ and $\mathbf{u}(t)$ denote the acceleration, velocity and displacement vector. Furthermore, $\tau$ is the mass influence vector while $\ddot{u}_{g}(t)$ represent the ground acceleration. As a result, $\mathbf{M}$ and $\mathbf{K}$ read,

$\mathbf{M}=\left[\begin{array}{cccc}m_{1}+m_{s} & 0 & 0 & 0 \\ 0 & m_{2} & 0 & 0 \\ 0 & 0 & m_{c} & 0 \\ 0 & 0 & 0 & m_{i}\end{array}\right] ; \quad \mathbf{K}=\left[\begin{array}{cccc}k_{1}+k_{2}+k_{c}+k_{i} & -k_{2} & -k_{c} & -k_{i} \\ -k_{2} & k_{2} & 0 & 0 \\ -k_{c} & 0 & k_{c} & 0 \\ -k_{i} & 0 & 0 & k_{i}\end{array}\right]$

$\mathbf{M}=\left[\begin{array}{cccccc}m_{1} & 0 & 0 & 0 & 0 & 0 \\ 0 & m_{2} & 0 & 0 & 0 & 0 \\ 0 & 0 & m_{1}+m_{s} & 0 & 0 & 0 \\ 0 & 0 & 0 & m_{2} & 0 & 0 \\ 0 & 0 & 0 & 0 & m_{c} & 0 \\ 0 & 0 & 0 & 0 & 0 & m_{i}\end{array}\right] ; \quad \mathbf{K}=\left[\begin{array}{cccccc}k_{1}+k_{2}+k_{1} & -k_{2} & -k_{1} & 0 & 0 & 0 \\ -k_{2} & k_{2} & 0 & 0 & 0 & 0 \\ -k_{1} & 0 & k_{1}+k_{2}+k_{c}+k_{i} & -k_{2} & -k_{c} & -k_{i} \\ 0 & 0 & -k_{2} & k_{2} & 0 & 0 \\ 0 & 0 & -k_{c} & 0 & k_{c} & 0 \\ 0 & 0 & -k_{i} & 0 & 0 & k_{i}\end{array}\right]$

for the Metafoundation with one- and two-layers, respectively.

More precisely, $m_{1}, m_{2}, k_{1}$ and $k_{2}$ denote the total mass of the cells, the mass of the resonators, the horizontal stiffness of all columns, and the stiffness of all springs attached to the resonators, respectively. Additionally, $m_{s}$ is assigned to the top slab of the Metafoundation. 


\subsection{Seismic design of the Metafoundation}

The construction site of the aforementioned foundation-tank system was chosen to be Priolo Gargallo (Italy), which is characterized by a peak ground acceleration PGA of $0.56 \mathrm{~g}$ for safe shutdown earthquake and soil type B. Since the foundation is supposed to remain undamaged even for SSE earthquakes, according to the conservative Italian code requirements for shallow foundations $\mathrm{s}^{35}$, the columns are designed to remain elastic for PGAs corresponding to a return period of 2475 years. The resulting stresses and modal displacements of the coupled system, see Figure 3, were combined with the complete quadratic-combination and provided a lower bound for the cross-sectional dimensions of the steel columns shown in Figure $4 b$.

As a result, four Metafoundations characterized by different combinations of layers and column heights were designed. The relevant geometrical characteristics are collected in Table 2 and the nomenclature can be found in Figure 4.

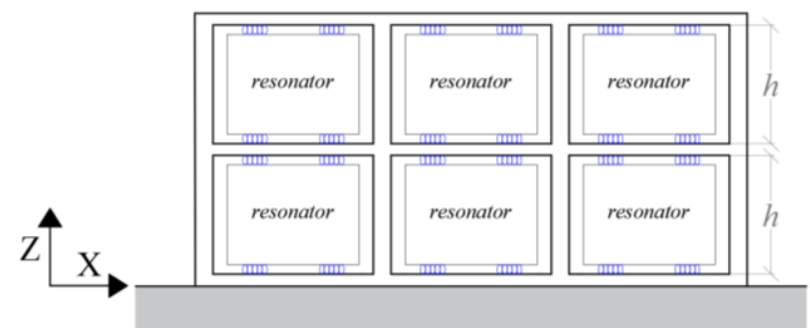

a)

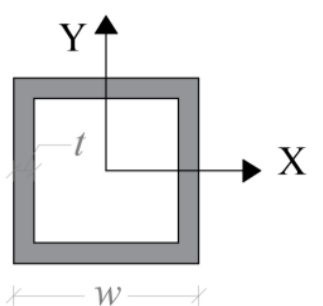

b)

Figure 4 Two-layer metafoundation: a) cross section of the foundation; b) cross section of a steel column.

Table 2 Geometrical characteristics of each foundation layout.

\begin{tabular}{ccccc}
\hline SECTION & L2H3 & L2H4 & L1H3 & L1H4 \\
\hline Number of layers & 2 & 2 & 1 & 1 \\
$h[\mathrm{~m}]$ & 1.5 & 2.0 & 3.0 & 4.0 \\
$w[\mathrm{~mm}]$ & 200 & 230 & 250 & 300 \\
$t[\mathrm{~mm}]$ & 30 & 30 & 30 & 30 \\
\hline
\end{tabular}

\subsection{Site-specific seismic hazard and accelerogram selection}

In order to evaluate the seismic activity of the construction site, i.e. Priolo Gargallo, two sets of natural accelerograms were selected with $10 \%$ and $5 \%$ probability of exceedance in 50 years, i.e. the so-called operating basis earthquakes (OBE) and safe shutdown earthquakes (SSE), respectively ${ }^{38}$. They are selected so that their mean spectrum fits in a least-square sense the uniform hazard spectrum (UHS), and are used in Section 6 for the validation of the metafoundation designs.

Although more sophisticated techniques are present in the literature, see for instance, the conditional mean spectrum $(\mathrm{CSM})^{39}$, the aforementioned UHS procedure is considered herein ${ }^{40}$. More precisely, methods like the CSM can reduce the dispersion of the response spectra at different periods, which is very important for a probabilistic analysis based on fragility functions. Nonetheless, the present work focuses on the feasibility of an innovative metamaterial-based design, and therefore, the UHS-based procedure suffices.

Both the response spectra of selected accelerograms and the UHS of Priolo Gargallo are shown in Figure 5; a careful reader can note that the seismic events exhibit a good mean fit of the UHS with a significant dispersion in frequency content. 

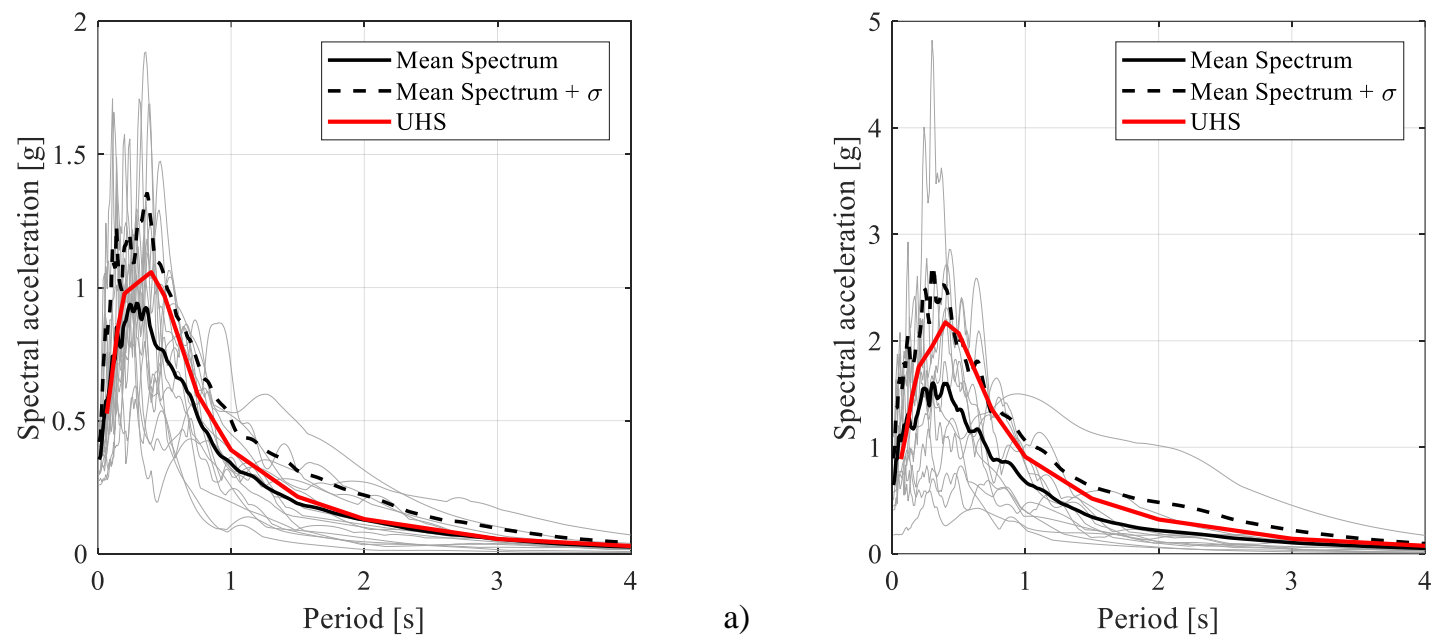

Figure 5 Response spectra of the selected accelerograms: a) UHS for OBE; b) UHS for SSE.

\section{UNCOUPLED SYSTEM PROPERTIES AND METAMATERIAL CONCEPT}

\subsection{Properties of a periodic lattice}

If the Metafoundation described in Subsection 2.2 can be designed as a periodic system, relevant unit cells can suppress the propagation of seismic waves in certain frequency regions. ${ }^{13-14}$ These regions are called band gaps and can be determined by means of a lattice dispersion analysis using the Floquet-Bloch theorem ${ }^{41}$. Under the aid of this theorem, it becomes possible to reduce the study of an infinite lattice to the analysis of a single unit cell with FloquetBloch quasi-periodic boundary conditions. After imposing these conditions, a frequency dispersion analysis can be carried out and the band gaps of the system can be found. According to the Floquet-Bloch theorem, the solution $\mathbf{u}(\mathbf{x}, \mathbf{t})$ for a periodic system reads,

$\mathbf{u}(\mathbf{x}, t)=\mathbf{u}_{k} e^{i(\mathbf{q x}-\omega t)}$

where $\mathbf{q}=\left[q_{x}, q_{y}, q_{z}\right]^{T}$ is the wave vector which becomes a scalar $q=q_{x}=2 \pi / \lambda$ in the uniaxial case, where $\lambda$ defines the wavelength, while $\omega$ represents the circular frequency. In the uniaxial case, the solution $\mathbf{u}(\mathbf{x}+\mathbf{R})$ of the periodic lattice becomes,

$u(x+R)=u e^{i q R}$

where $\mathrm{R}$ is the lattice constant. Furthermore, in order to apply these conditions, the EOMs of a typical cell need to be considered,

$m_{2}^{j} \frac{d^{2} u_{1}^{j}}{d t^{2}}-k_{1} u_{1}^{j-1}+k_{1} u_{1}^{j}+k_{2} u_{1}^{j}+k_{1} u_{1}^{j}-k_{2} u_{2}^{j}-k_{1} u_{1}^{j+1}=0$

$m_{2}^{j} \frac{d^{2} u_{2}^{j}}{d t^{2}}-k_{2} u_{1}^{j}+k_{2} u_{2}^{j}=0$

where $m_{i}, k_{i}$, and $u_{i}$ denote masses, stiffnesses and displacements of both cells and resonators indicated in Figure 6a, while the superscript $j$ determines the position of the unit cell, i.e. $j$, unit cell under study, $j-1$, unit cell below and $j+1$ : unit cell above. It is now possible to apply the boundary conditions to both (9) and (10) and formulate the discrete eigenvalue problem as, 


$$
\left(\mathbf{K}-\omega^{2} \mathbf{M}\right) \mathbf{u}=\mathbf{0}
$$

The non-trivial solutions of (11) with applied boundary conditions entail the following dispersion relationship,

$$
m_{1} m_{2} \omega^{4}-\left[\left(m_{1}+m_{2}\right) k_{2}+2 m_{2} k_{1}(1-\cos (q R))\right] \omega^{2}+2 k_{1} k_{2}(1-\cos (q R))=0
$$

Thus, Figure 6 illustrates the dispersion relation and corresponding band gap of an infinite periodic stack of unit cells for the configuration L2H4 presented in Subsection 2.3. Clearly, a band gap forms in the frequency range of 1-1.7 Hz, which according to the Floquet-Bloch theorem does not allow the propagation of elastic waves.

However, this result is only valid for an infinite lattice. Therefore, additional analyses are presented hereinafter for the case of a finite foundation.

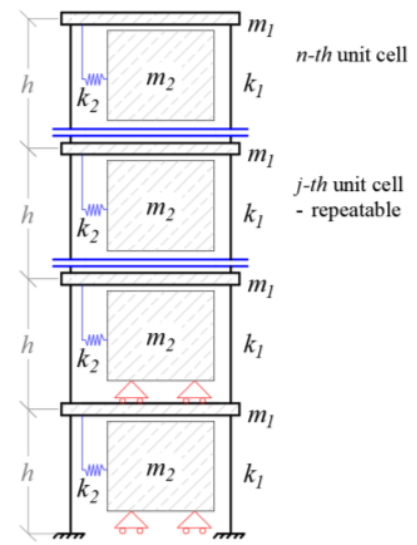

a)

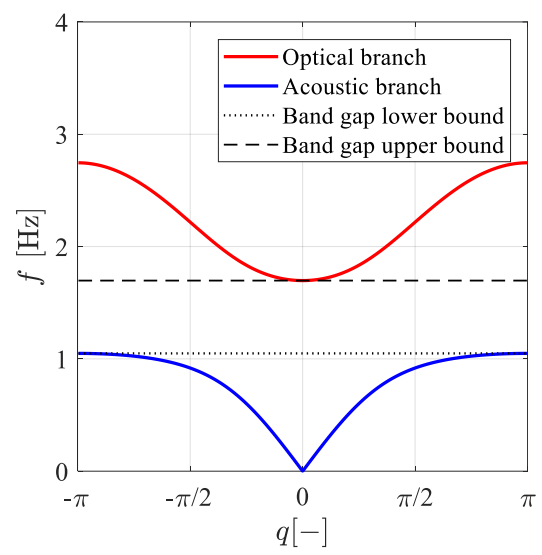

b)

\section{Figure 6 a) 1D mass-resonator chain model. b) dispersion relation for an infinite stack of unit cells with the geometric properties of $\mathrm{L2H} 4$.}

\subsection{Concept of seismic isolation and negative apparent mass}

Another well-known concept for the protection of critical infrastructures is seismic isolation ${ }^{42}$. In this regard, the linear theory of seismic isolation ${ }^{42}$ entails that the dynamic response of a base-isolated structure is governed by the parameter $\varepsilon=\omega_{\mathrm{b}}{ }^{2} / \omega_{\mathrm{s}}{ }^{2}$, where $\omega_{\mathrm{b}}$ is the frequency of the base-isolated structure and $\omega_{\mathrm{s}}$ is the fundamental frequency of the fixed-base structure. If $\varepsilon$ is of the order of $10^{-2}$ or less, the design of the seismic isolation can be considered effective. For the case at hand, the impulsive mode of the tank, described in Subsection 2.1. is the one of interest. Therefore, $\omega_{s}$ becomes the impulsive frequency of the uncoupled system, i.e. $\omega_{s}=\omega_{i}$ and $\omega_{b}$ defines the frequency of the impulsive mass $m_{i}$ of the tank.

With regard to the coupled system, see Figure 3, it becomes evident that the stiffness of the columns has a direct influence on $\varepsilon$. In fact, note that a weakening of the columns entails a reduction of $\varepsilon$, which in turns improves the isolation behavior of the coupled system. Hence, the elastic design of the Metafoundation discussed in Subsection 2.3, provides a minimum value for the columns cross-section, and therefore, governs the horizontal stiffness value.

Furthermore, to exploit the negative apparent mass concept ${ }^{43}$, we consider resonators endowed with masses larger than the one of the unit cell, as shown in Figure 7a. The apparent mass of the system $\mathrm{M}_{\text {app }}(\omega)$ depicted in Figure $7 \mathrm{~b}$ reads,

$M_{a p p}(\omega)=m_{1}-\frac{k_{1}}{\omega^{2}}+\frac{k_{2}}{\omega_{2}^{2}-\omega^{2}}$

where $\omega_{2}$ is the frequency of the resonator and $\omega$ represents the forcing frequency. It is clear from Figure 7b, that the effective mass becomes negative when the forcing frequency is near to the resonance one. Since the acceleration response is opposing to the applied force, the response amplitude is reduced. This effect is greatly magnified as the input frequency $\omega$ approaches the local resonance frequency $\omega_{2}$. 


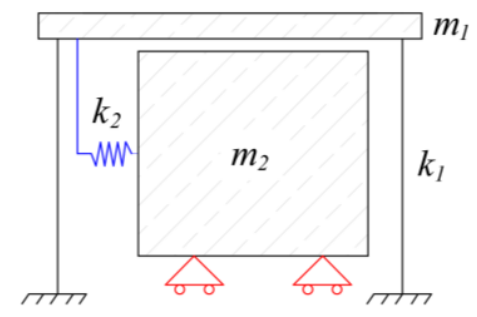

a)

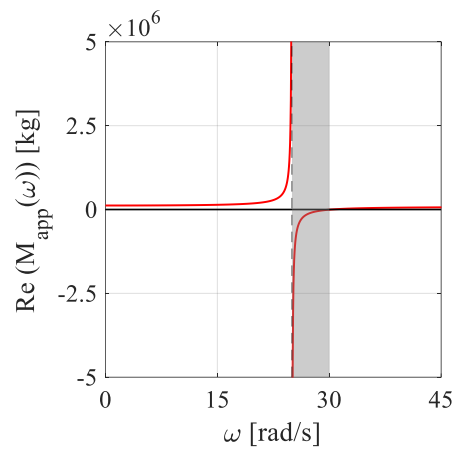

b)

Figure 7 a) Schematization of a unit cell; b) Apparent mass as a function of forcing frequency.

\section{OPTIMZATION PROCEDURE OF THE METAFOUNDATION}

Metamaterials are typically designed for their band gap properties. However, for a finite lattice the interaction of the metamaterial with the superstructure can have a significant impact on its dynamic behavior. ${ }^{27}$ Furthermore, it is established that the frequency content of an earthquake is highly site specific and may change significantly for different sites. Therefore, to take these issues into account, we propose two optimization procedures herein, that are able to optimize the coupled system, for a specific frequency content and a chosen superstructure. In particular, these procedures evaluate the optimal parameters of the resonators, namely $k_{2}$ and $\zeta_{2}$.

With regard to $m_{2}$, based on both the considerations of Subsection 3.2 on the apparent mass, and the main limitation of TMDs, being the low mass of the damper ${ }^{34,44}$, we design the resonators to exert the largest mass compatible with the unit cell dimensions. As a result, the remaining free parameters in the optimization procedure are: i) the stiffness $k_{2}$ of each resonator; ii) the damping ratio $\zeta_{2}$ of each resonator.

\subsection{Ground motion modelling}

In a first step, the earthquake ground motions are modelled as a stationary Gaussian filtered white noise random process with zero mean and spectral intensity $S_{0}$. In this respect, Kanai and Tajimi ${ }^{45}$ proposed an analytical formulation able to simulate a site specific PSD, which has later been modified by Clough and Penzien ${ }^{46}$. This formulation is based on the Kanai-Tajimi filter modified by Clough and Penzien and, for brevity, is referred to as KTCP. The KTCP filter is evaluated as,

$H_{K T C P}^{2}(i \omega)=H_{C P}^{2}(i \omega) H_{K T}^{2}(i \omega)$

where $H_{C P}(i \omega)$ attenuates the very low-frequency component introduced by Clough and Penzien, and $H_{K T}(i \omega)$ denotes the soil filter suggested by Kanai and Tajimi. The filters read,

$H_{C P}(i \omega)=\frac{\frac{\omega^{2}}{\omega_{1}^{2}}}{\left(1-\frac{\omega^{2}}{\omega_{1}^{2}}\right)+2 i \zeta_{g} \frac{\omega}{\omega_{g}}}$

$H_{K T}(i \omega)=\frac{1+2 i \zeta_{g} \frac{\omega}{\omega_{g}}}{\left(1-\frac{\omega^{2}}{\omega_{g}^{2}}\right)+2 i \zeta_{g} \frac{\omega}{\omega_{g}}}$

where $\omega_{g}$ and $\zeta_{g}$ are the frequency and damping ratio that describe the characteristics of the soil, while $\omega_{1}$ and $\zeta_{1}$ denote the parameters of the low pass filter introduced by Clough and Penzien. 


\subsection{Optimization procedures in the frequency domain}

The evaluation of the response of the coupled system is evaluated in the frequency domain herein. Hence, the system of EOMs of the coupled foundation-tank system can be written as,

$$
\begin{aligned}
& \mathbf{M u}(t)+\mathbf{C u}(t)+\mathbf{K u}(t)-\mathbf{Y}(t)=-\mathbf{M} \boldsymbol{\sim} \ddot{u}_{g}(t) \\
& m_{j l} \ddot{y}_{j l}(t)+m_{j l} 2 \zeta_{r l} \omega_{r l} \dot{y}_{j l}(t)+m_{j l} \omega_{r l}^{2} y_{j l}(t)=-m_{j l}\left[\ddot{u}_{g}(t)+\ddot{u}_{j}(t)\right]
\end{aligned}
$$

where $\mathbf{Y}(\mathrm{t})$ is the force vector applied to the Metafoundation by the resonators; $\ddot{y}_{j l}(t), \dot{y}_{j l}(t)$ and $y_{j l}(t)$ define the acceleration, velocity and displacement of the $l$-th resonator on the $j$-th layer, while, $m_{j l}, \zeta_{r l}$ and $\omega_{r l}$ represent the mass, damping ratio and frequency of the resonators, respectively. We condense the masses of the resonators of each layer as shown in the Subsection 2.2. Therefore, the $j$-th component of the vector $\mathbf{Y}(\mathrm{t})$ can be evaluated as,

$$
\sum_{l=1}^{N_{r}} m_{j l}\left[2 \zeta_{r l} \omega_{r l} \dot{y}_{j l}(t)+\omega_{r l}^{2} y_{j l}(t)\right]
$$

where $N_{r}$ is the number of resonators in each layer. Through modal transformation, the displacement vector $\mathbf{u}(\mathrm{t})$ can be defined as,

$\mathbf{u}(t)=\mathbf{\Phi q}(t)$

where $\mathbf{q}(t)$ is the vector that represents the generalized coordinates of the coupled system, while $\boldsymbol{\Phi}$ denotes the eigenvector matrix. Substituting (20) in (17) and premultiplying by $\Phi^{T}$, the $j$-th equation of motion becomes,

$\ddot{q}_{k}(t)+2 \zeta_{k} \omega_{k} \dot{q}_{k}(t)+\omega_{k}^{2} q_{k}(t)-\sum_{j=1}^{N} \varphi_{k}(j) \sum_{l=1}^{N_{r}} m_{j l}\left[2 \zeta_{r l} \omega_{r l} \dot{y}_{j l}(t)+\omega_{r l}^{2} y_{j l}(t)\right]=-\Gamma_{k} \ddot{u}_{g}(t)$

where $\mathrm{q}_{k}(t), \zeta_{k}, \omega_{k}, \Gamma_{k}$, and $\varphi_{k}(j)$ are the generalized coordinate, damping ratio, eigenfrequency, mass participation factor, and mode value, of the $k$-th mode at the $j$-th layer, respectively.

In order to obtain the transfer functions of the system, we define ground acceleration, modal displacement, displacement and forcing term as $\ddot{u}_{g}(t)=e^{i \omega t}, q_{k}(t)=T_{q_{k}}(i \omega) e^{i \omega t}, u_{j}(t)=T_{u_{j}}(i \omega) e^{i \omega t}$ and $y_{j l}(t)=T_{y_{j l}}(i \omega) e^{i \omega t}$, respectively, assuming a unit amplitude for $\ddot{u}_{g}(t)$. Substituting these relationships into (20) and (17), we obtain,

$$
\begin{aligned}
& \frac{T_{q_{k}}(i \omega)}{H_{k}(i \omega)}-\sum_{j=1}^{N} \varphi_{k}(j) \sum_{l=1}^{N_{r}} m_{j l}\left[i 2 \zeta_{r l} \omega_{r l} \omega+\omega_{r l}^{2}\right] T_{y_{j l}}(i \omega)=-\Gamma_{k} \\
& \frac{T_{y_{j l}}(i \omega)}{H_{r l}(i \omega)}=-1+\omega^{2} T_{u_{j}}(i \omega)
\end{aligned}
$$

where $H_{k}(\omega)$ and $H_{r l}(\omega)$ define the transfer functions of an SDoF system,

$$
\begin{aligned}
& H_{k}(i \omega)=\frac{1}{\left(\omega_{k}^{2}-\omega+i 2 \zeta_{k} \omega_{k} \omega\right)} \\
& H_{r l}(i \omega)=\frac{1}{\left(\omega_{r l}^{2}-\omega+i 2 \zeta_{r l} \omega_{r l} \omega\right)}
\end{aligned}
$$


The modal transformation (20) combined to (22) and (23) entail the displacement transfer function $T_{u_{j}}(i \omega)$ of (23). Subsequently, the transfer functions of the interstorey drift $D_{j}(i \omega)$, relative velocity $V_{j}(i \omega)$ and absolute acceleration $A_{j}(i \omega)$ can be evaluated as,

$$
\begin{aligned}
& D_{j}(i \omega)=T_{u_{j}}(i \omega)-T_{u_{j-1}}(i \omega) \\
& V_{j}(i \omega)=i \omega T_{u_{j}}(i \omega) \\
& A_{j}(i \omega)=1-\omega^{2} T_{u_{j}}(i \omega)
\end{aligned}
$$

Hence, the power spectral density (PSD) of $\mathrm{u}(\mathrm{t})$ can be evaluated as,

$$
S_{u u}(\omega)=\left|H_{u u}(i \omega)\right|^{2} S_{K T C P}(\omega)
$$

where $S_{u и}(\omega)$ denotes the PSD of $\mathrm{u}(\mathrm{t})$, while $H_{u и}(i \omega)$ represents a generic transfer function of the coupled system. Furthermore, based on the Wiener-Khintchine transformations, the autocorrelation function $R_{u u}(\tau)$ the variance $\sigma^{2}$ of a generic response can be calculated as,

$$
\sigma_{u u}^{2}=R_{u u}(0)=\int_{-\infty}^{+\infty} S_{u u}(\omega) d \omega
$$

Hence, the variance of drift $\sigma_{D_{j}}^{2}$, velocity $\sigma_{V_{j}}^{2}$ and absolute acceleration $\sigma_{A_{j}}^{2}$ at the $j$-th layer can be computed by means of (27) and (28) as,

$$
\begin{aligned}
& \sigma_{D_{j}}^{2}=\int_{0}^{+\infty}\left|D_{j}(i \omega)\right|^{2} H_{K T C P}^{2}(\omega) d \omega \\
& \sigma_{V_{j}}^{2}=\int_{0}^{+\infty}\left|V_{j}(i \omega)\right|^{2} H_{K T C P}^{2}(\omega) d \omega \\
& \sigma_{A_{j}}^{2}=\int_{0}^{+\infty}\left|A_{j}(i \omega)\right|^{2} H_{K T C P}^{2}(\omega) d \omega
\end{aligned}
$$

\subsection{Optimization parameters}

In order to compute the optimal parameters of the resonators, we can use the variances of the responses of the coupled system defined in (28). More precisely, to evaluate the effectiveness of the Metafoundation and the optimal stiffness and damping ratio of the system, two parameters, the Performance Index PI and the Energy Dissipation Index EDI are defined based on: i) the reduction of the absolute acceleration of the impulsive mass $\mathrm{m}_{i}$; ii) the energy dissipated by the resonators.

The performance index PI, it can be defined as,

$\operatorname{PI}\left(\zeta_{2}, \omega_{2}\right)=\frac{\sigma_{A_{i}}^{2}\left(\zeta_{2}, \omega_{2}\right)}{\sigma_{A_{i}}^{2 \text { fix }}}$

where $\sigma_{A_{i}}^{2}$ is the variance of the absolute acceleration of the impulsive mass of the coupled system as a function of

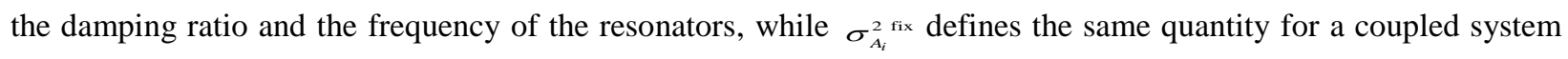
with a fixed base. As a result, the optimal values of the unknown parameters are obtained reducing the absolute acceleration of the impulsive mass of the superstructure as follows, 
$\zeta_{2}^{o p t}, \omega_{2}^{o p t}=\min \left[\mathrm{PI}\left(\zeta_{2}, \omega_{2}\right)\right]$

As far as the energy dissipation index EDI is concerned, it is based on the dissipated energy by the resonators with respect to the input energy ${ }^{34}$. In this case, the $j$-th equation of motion can be written in terms of relative energy balance by multiplying each term by the velocity of the $j$-th degree of freedom and then integrating over time, yielding,

$E_{k_{j}}(t)+E_{d_{j}}(t)+E_{e_{j}}(t)=E_{i_{j}}(t)+E_{f_{j}}(t)$

where $E_{k_{j}}(t)$ is the relative kinetic energy, $E_{d_{j}}(t)$ defines the energy dissipated by viscous damping, $E_{e_{j}}(t)$ is the elastic strain energy, $E_{i_{j}}(t)$ represents the relative input energy and $E_{f_{j}}(t)$ is the energy flowing between the degrees of freedom. Since the seismic input is a stochastic process, (31) has to be formulated in terms of expected values as,

$$
\mathrm{E}\left[E_{k_{j}}\right]+\mathrm{E}\left[E_{d_{j}}\right]+\mathrm{E}\left[E_{e_{j}}\right]=\mathrm{E}\left[E_{i_{j}}\right]+\mathrm{E}\left[E_{f_{j}}\right]
$$

In particular, if we consider the conservation of mechanical energy in a finite time increment $\Delta t$, (33) becomes,

$$
\mathrm{E}\left[\Delta E_{d_{j}}\right]-\mathrm{E}\left[\Delta E_{f_{j}}\right]=\mathrm{E}\left[\Delta E_{i_{j}}\right]
$$

Reggio and De Angelis ${ }^{34}$ proved that the relative input energy of the system is equal to the dissipated one, thus resulting in,

$$
\sum_{j=1}^{N} \mathrm{E}\left[E_{f_{j}}\right]=0
$$

where $N$ defines the degree of freedom of the system. Thus, the EDI can be expressed as,

$$
\operatorname{EDI}\left(\zeta_{2}, \omega_{2}\right)=\frac{\sum_{r=1}^{N_{r}} \mathrm{E}\left[\Delta E d_{r}\left(\zeta_{2}, \omega_{2}\right)\right]}{\sum_{j=1}^{N} \mathrm{E}\left[\Delta E d_{j}\left(\zeta_{2}, \omega_{2}\right)\right]}
$$

More details about the evaluation of these terms can be found in ${ }^{34}$.

In sum, the optimal damping ratio $\zeta_{2}^{\text {opt }}$ and frequency parameter $\omega_{2}{ }^{\text {opt }}$ are obtained by maximizing the energy dissipated by the resonators with respect to the one dissipated by the whole coupled system,

$$
\zeta_{2}^{o p t}, \omega_{2}^{o p t}=\max \left[\operatorname{EDI}\left(\zeta_{2}, \omega_{2}\right)\right]
$$

\section{RESULTS OF METAFOUNDATION OPTMIZATIONS}

In order to apply the optimization procedures described in the previous Section, three different types of soils - soft, medium and rock soil ${ }^{47}$ - modeled with the KTCP filter are considered, as shown in Figure 8a. Furthermore, to evaluate the PSD of the ground motions representative for the construction site, the procedure described in APPENDIX 1 is applied to the seismic records selected in Subsection 2.4. Thus, in order to fit the PSD functions that characterize the OBE and SSE events, the parameters of the KTCP filter $\left(\mathrm{S}_{0}, \omega_{\mathrm{g}}, \zeta_{\mathrm{g}}, \omega_{1}\right.$ and $\left.\zeta_{1}\right)$ were evaluated. The resulting PSD functions and the fitted KTCP filtered estimates are shown in Figure 8b and Figure 8c, respectively, while Table 3 displays the relevant parameters. 


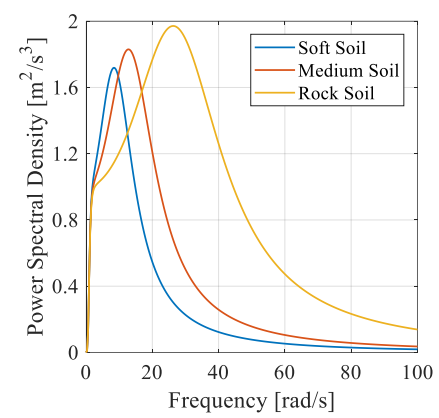

a)

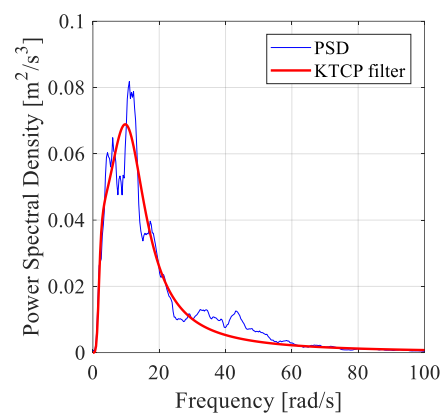

b)

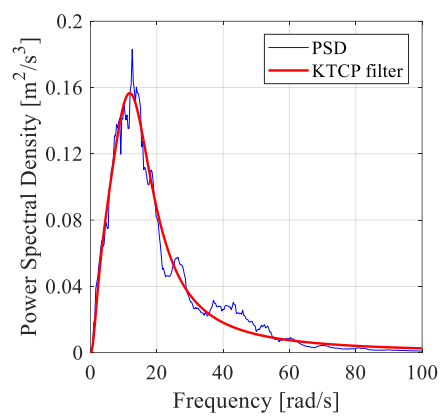

c)

Figure 8 PSD functions of filtered white noises: a) KTCP filter for three types of soil; b) average PSD and KTCP fit for OBE events; c) average PSD and KTCP fit for SSE events

Table 3 Parameters of the KTCP filter.

\begin{tabular}{cccccc}
\hline Type of soil & $\begin{array}{c}\mathrm{S}_{0} \\
{\left[\mathrm{~m}^{2} / \mathrm{s}^{3}\right]}\end{array}$ & $\begin{array}{c}\omega_{\mathrm{g}} \\
{[\mathrm{rad} / \mathrm{s}]}\end{array}$ & $\zeta_{\mathrm{g}}$ & $\begin{array}{c}\omega_{1} \\
{[\mathrm{rad} / \mathrm{s}]}\end{array}$ & $\zeta_{1}$ \\
\hline Soft & 1.0 & 10.5 & 0.65 & 1.0 & 0.7 \\
\hline Medium & 1.0 & 15.6 & 0.60 & 1.0 & 0.7 \\
\hline Rock & 1.0 & 31.4 & 0.55 & 1.0 & 0.7 \\
\hline Priolo Gargallo (OBE) & 0.037 & 12.0 & 0.60 & 2.0 & 0.62 \\
\hline Priolo Gargallo (SSE) & 0.090 & 14.0 & 0.60 & 0.75 & 1.90 \\
\hline
\end{tabular}

The optimization procedure is carried out for each Metafoundation described in Table 2. Thus, with reference to the L1H4 foundation with a slender tank, typical results are depicted in Figure 9, that shows both the surface and the contour line of PI, respectively, corresponding to the SSE case for the Priolo Gargallo site. The same information is illustrated in Fig. 10 for EDI.

In order to select the optimal combination of coupled Metafoundation-tank systems, taking into account different soil properties, 4 different foundations with 2 distinct tanks, as described in Subsection 2.1 and 2.3, are subjected to 5 different PSDs and evaluated by means of PI and EDI parameters. Thus, Tables 4 and 5 summarize the optimal parameter values $\zeta_{2}^{o p t}$ and $\omega_{2}{ }^{o p t}$ of the resonators for slender and broad tanks, respectively. The results show that PI and EDI yield very similar optimal frequencies for the resonators, while the optimal damping ratio is found to be higher for the EDI approach. Clearly, this is related to the fact that the EDI parameter focuses on the amount of energy that is being dissipated by the resonators. A better comparison between the results provided by the two indices can be done after time history analyses carried out in Section 6.

The results of the optimization also confirm the effectiveness of the isolation effect provided by the unit cells. With regard to the PI and EDI values of the system for different foundations, while also observing the isolation parameter $\varepsilon$, it becomes clear that the Metafoundation reduces stresses not only due to its metamaterial like or TMD like properties, but also because of its capability to exert a limited amount of seismic isolation. As a result, the L1H4 foundation performs better in terms of both PI and EDI due to its small epsilon value.

With regard to the ground-metafoundation coupling, more flexible foundations perform better in firm soils due to the maximum decoupling between soil and foundation frequency content. The best performance is obtained for the L1H4 foundation with rock soil for both PI and EDI values.

When comparing the parameters of the KTCP fitted PSD obtained for the Priolo Gargallo soil to the standard KTCP soil filters, see Table 3, it becomes apparent that the Priolo Gargallo site is in between medium and soft soil. Moreover, Table 4 shows that similar optimal resonator parameters are obtained for both Priolo Gargallo soils. 

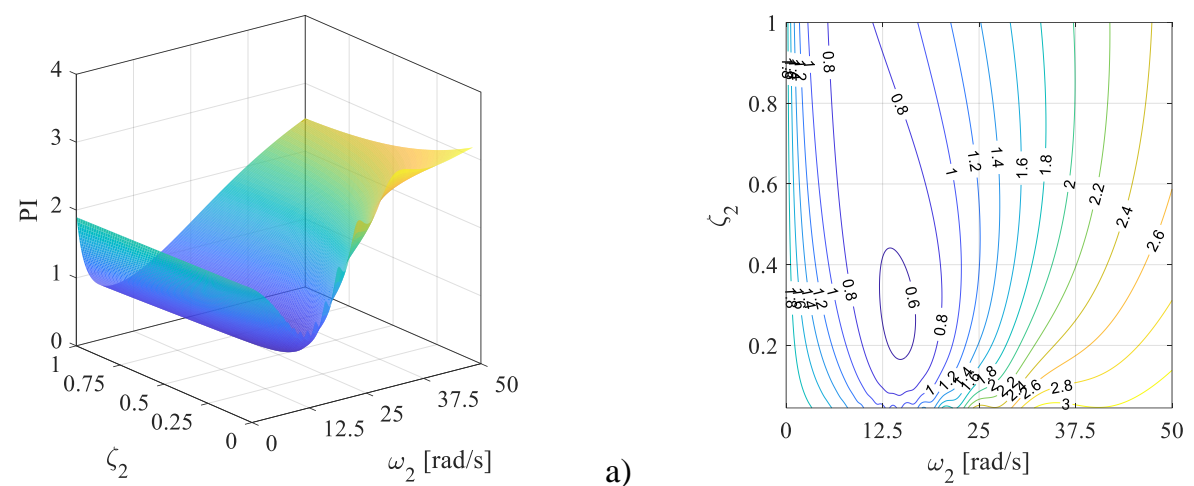

b)

Figure 9 PI optimization of a slender tank on an L1H4 foundation with SSE records: a) optimization surface vs. resonator parameters; b) contour lines of the optimization surface
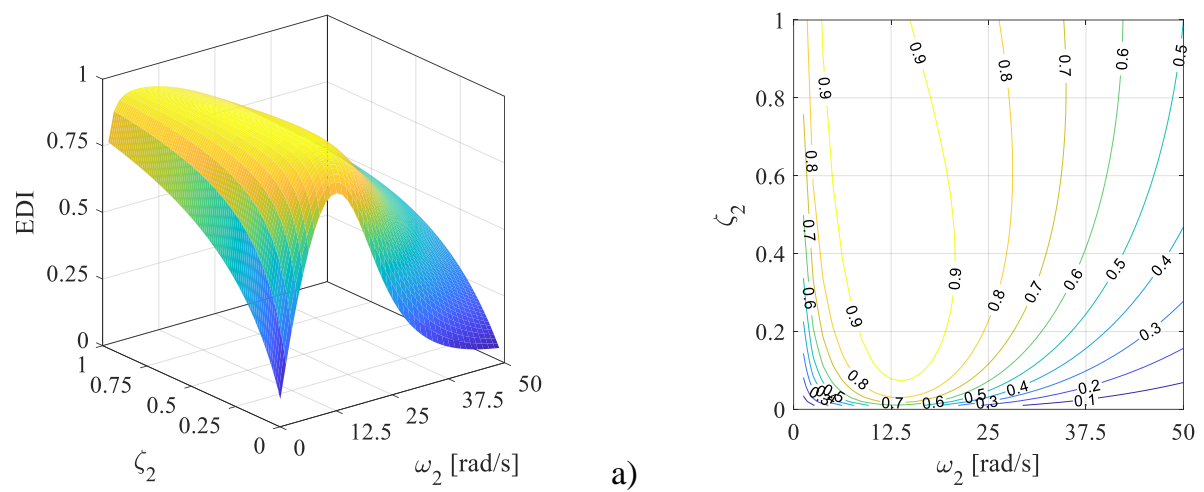

b)

Figure 10 EDI optimization of a slender tank on an L1H4 foundation with SSE records: a) optimization surface vs. resonator parameters; b) contour lines of the optimization surface

Table 4 Optimal parameters based on both PI and EDI for the slender tank.

\begin{tabular}{|c|c|c|c|c|c|c|c|c|c|}
\hline \multirow[t]{2}{*}{ Type of soil } & \multirow{2}{*}{$\begin{array}{c}\text { Optimal } \\
\text { Parameters }\end{array}$} & \multicolumn{2}{|c|}{$\begin{array}{c}\text { L2H3 } \\
\varepsilon=0.48\end{array}$} & \multicolumn{2}{|c|}{$\begin{array}{c}\text { L2H4 } \\
\varepsilon=0.38\end{array}$} & \multicolumn{2}{|c|}{$\begin{array}{c}\mathrm{L} 1 \mathrm{H} 3 \\
\varepsilon=0.33\end{array}$} & \multicolumn{2}{|c|}{$\begin{array}{c}\text { L1H4 } \\
\varepsilon=0.27\end{array}$} \\
\hline & & PI & EDI & PI & EDI & PI & EDI & PI & EDI \\
\hline \multirow{3}{*}{ SOFT } & $\zeta_{2}{ }^{o p t}$ & 0.17 & 0.20 & 0.22 & 0.28 & 0.25 & 0.29 & 0.29 & 0.33 \\
\hline & $\omega_{2}^{\text {opt }}[\mathrm{rad} / \mathrm{s}]$ & 24.40 & 22.62 & 19.60 & 16.34 & 17.20 & 15.08 & 14.00 & 11.31 \\
\hline & index & 0.80 & 0.85 & 0.76 & 0.92 & 0.70 & 0.92 & 0.65 & 0.94 \\
\hline \multirow{3}{*}{ MEDIUM } & $\zeta 2^{o p t}$ & 0.17 & 0.18 & 0.21 & 0.23 & 0.24 & 0.27 & 0.26 & 0.30 \\
\hline & $\omega 2^{\text {opt }}[\mathrm{rad} / \mathrm{s}]$ & 24.30 & 23.88 & 19.70 & 18.85 & 17.60 & 16.34 & 15.10 & 13.82 \\
\hline & index & 0.78 & 0.88 & 0.70 & 0.93 & 0.61 & 0.93 & 0.52 & 0.94 \\
\hline \multirow{3}{*}{ ROCK } & $\zeta 2^{o p t}$ & 0.15 & 0.17 & 0.20 & 0.24 & 0.25 & 0.28 & 0.31 & 0.33 \\
\hline & $\omega_{2}^{\text {opt }}[\mathrm{rad} / \mathrm{s}]$ & 26.00 & 26.39 & 22.10 & 21.36 & 20.10 & 18.85 & 17.00 & 15.08 \\
\hline & index & 0.44 & 0.87 & 0.31 & 0.91 & 0.23 & 0.90 & 0.17 & 0.95 \\
\hline \multirow{3}{*}{$\begin{array}{l}\text { Priolo Gargallo } \\
T_{R}=475 \text { years }\end{array}$} & $\zeta_{2}{ }^{o p t}$ & 0.17 & 0.20 & 0.22 & 0.25 & 0.25 & 0.28 & 0.28 & 0.30 \\
\hline & $\omega_{2}{ }^{\text {opt }}[\mathrm{rad} / \mathrm{s}]$ & 24.30 & 22.62 & 19.40 & 17.59 & 17.00 & 15.08 & 14.00 & 12.57 \\
\hline & index & 0.82 & 0.87 & 0.79 & 0.93 & 0.72 & 0.93 & 0.66 & 0.95 \\
\hline \multirow{3}{*}{$\begin{array}{l}\text { Priolo Gargallo } \\
T_{R}=2475 \text { years }\end{array}$} & $\zeta_{2}^{o p t}$ & 0.17 & 0.18 & 0.21 & 0.24 & 0.24 & 0.27 & 0.27 & 0.29 \\
\hline & $\omega_{2}{ }^{\text {opt }}[\mathrm{rad} / \mathrm{s}]$ & 24.30 & 23.88 & 19.50 & 18.85 & 17.40 & 16.34 & 14.60 & 13.82 \\
\hline & index & 0.79 & 0.89 & 0.73 & 0.94 & 0.65 & 0.94 & 0.56 & 0.95 \\
\hline
\end{tabular}

The optimization procedure for the broad tank provides lower values for $\zeta_{2}^{\text {opt }}$ and $\omega_{2}{ }^{\text {opt }}$ compared to the slender tank, since it has a different geometry and, therefore, exerts lower eigenfrequencies.

However, analogously to the slender tank, also the broad tank shows better results for a more flexible foundation in firm soils. Note that more favorable results are obtained for the broad tank, with respect to the slender one, despite the increased $\varepsilon$ value. This is due to the decoupling of the eigenfrequency of the coupled system and the frequency content of the soil filter. In addition, the results show that the fitted KTCP filtered soils are located between medium and soft soil types. 
Table 5 Optimal parameters based on both PI and EDI for the broad tank.

\begin{tabular}{|c|c|c|c|c|c|c|c|c|c|}
\hline \multirow[t]{2}{*}{ Type of soil } & \multirow{2}{*}{$\begin{array}{c}\text { Optimal } \\
\text { Parameters }\end{array}$} & \multicolumn{2}{|c|}{$\begin{array}{c}\mathrm{L} 2 \mathrm{H} 3 \\
\varepsilon=0.77\end{array}$} & \multicolumn{2}{|c|}{$\begin{array}{c}\text { L2H4 } \\
\varepsilon=0.69\end{array}$} & \multicolumn{2}{|c|}{$\begin{array}{c}\mathrm{L} 1 \mathrm{H} 3 \\
\varepsilon=0.63\end{array}$} & \multicolumn{2}{|c|}{$\begin{array}{c}\text { L1H4 } \\
\varepsilon=0.57\end{array}$} \\
\hline & & PI & EDI & PI & EDI & PI & EDI & $\mathrm{PI}$ & EDI \\
\hline \multirow{3}{*}{ SOFT } & $\zeta_{2}{ }^{o p t}$ & 0.08 & 0.10 & 0.14 & 0.16 & 0.18 & 0.21 & 0.23 & 0.27 \\
\hline & $\omega_{2}{ }^{o p t}[\mathrm{rad} / \mathrm{s}]$ & 18.70 & 18.85 & 16.90 & 16.34 & 15.30 & 15.08 & 13.20 & 12.57 \\
\hline & index & 0.79 & 0.80 & 0.71 & 0.88 & 0.64 & 0.89 & 0.56 & 0.91 \\
\hline \multirow{3}{*}{ MEDIUM } & $\zeta_{2}{ }^{\text {opt }}$ & 0.08 & 0.10 & 0.13 & 0.14 & 0.18 & 0.20 & 0.23 & 0.27 \\
\hline & $\omega_{2}{ }^{o p t}[\mathrm{rad} / \mathrm{s}]$ & 18.80 & 18.85 & 17.00 & 17.59 & 15.80 & 16.34 & 14.10 & 13.82 \\
\hline & index & 0.72 & 0.80 & 0.60 & 0.88 & 0.52 & 0.88 & 0.42 & 0.92 \\
\hline \multirow{3}{*}{ ROCK } & $\zeta_{2}$ opt & 0.09 & 0.09 & 0.14 & 0.14 & 0.17 & 0.20 & 0.22 & 0.28 \\
\hline & $\omega 2^{o p t}[\mathrm{rad} / \mathrm{s}]$ & 20.10 & 20.11 & 17.90 & 18.85 & 17.70 & 17.59 & 15.90 & 15.08 \\
\hline & index & 0.49 & 0.75 & 0.36 & 0.84 & 0.28 & 0.84 & 0.21 & 0.94 \\
\hline \multirow{3}{*}{$\begin{array}{c}\text { Priolo Gargallo } \\
\mathrm{T}_{\mathrm{R}}=475 \text { years }\end{array}$} & $\zeta_{2}{ }^{o p t}$ & 0.10 & 0.10 & 0.15 & 0.15 & 0.19 & 0.21 & 0.23 & 0.27 \\
\hline & $\omega_{2}{ }^{o p t}[\mathrm{rad} / \mathrm{s}]$ & 18.90 & 18.85 & 16.70 & 16.34 & 15.50 & 15.08 & 13.40 & 12.57 \\
\hline & index & 0.78 & 0.81 & 0.70 & 0.89 & 0.62 & 0.90 & 0.53 & 0.93 \\
\hline \multirow{3}{*}{$\begin{array}{l}\text { Priolo Gargallo } \\
T_{R}=2475 \text { years }\end{array}$} & $\zeta_{2}{ }^{o p t}$ & 0.09 & 0.10 & 0.14 & 0.14 & 0.18 & 0.20 & 0.23 & 0.26 \\
\hline & $\omega_{2}{ }^{o p t}[\mathrm{rad} / \mathrm{s}]$ & 19.00 & 18.85 & 16.90 & 17.59 & 15.90 & 16.34 & 13.90 & 13.82 \\
\hline & index & 0.73 & 0.81 & 0.63 & 0.89 & 0.54 & 0.89 & 0.44 & 0.92 \\
\hline
\end{tabular}

\section{STRUCTURAL RESPONSES PROVIDED BY TIME HISTORY ANALYSES}

In order to evaluate the performance of the proposed Metafoundation under realistic ground motions, THAs were carried out for the OBE and SSE events. The base shear of the tank was assumed to be the governing factor for the performance of the system and can be calculated as follows,

$V=k_{i}\left(u_{i}-u_{t l}\right)+k_{c}\left(u_{c}-u_{t l}\right)$

where $u_{i}, u_{c}$ and $u_{t l}$ denote the displacement of the impulsive mass, the displacement of the convective mass, and the displacement of the top layer of the foundation, which coincides with the bottom of the tank, respectively. As a result, the reduction of the tank base shear due to the presence of a Metafoundation can be evaluated as,

$\alpha^{(i)}=\frac{V_{R M S}^{(i)}}{V_{R M S, f i x}^{(i)}}$

where $V_{R M S}$ and $V_{R M S \text {,fix }}$ are the root mean square (RMS) values of the base shear of a tank on a Metafoundation and a tank on a fixed-base foundation, while $i$ denotes the seismic event under study. This index displays the stress reduction of the Metafoundation with respect to a traditional foundation.

\subsection{Results for the coupled foundation-slender tank system}

Herein, Figure 11 shows the RMS of the base shear of the coupled system subjected to SSE events. More precisely, it compares the results of the Metafoundation optimized with PI and EDI with the response of a fixed-base tank. It is worth noting that the results of the THAs show a high dispersion for the base shear when correlated with the PGA. This is due to the wide variety of frequency and amplitude content of the accelerograms and the possibility that the PGA may not serve as an optimal intensity measure for the present analysis, as shown in Figure 5. However, since the interest is not on a fragility analysis of the system, the PGA has been considered as a sufficient parameter for result interpretation. A linear regression of the base shear against the PGA, presented in Figure 11, shows that the Metafoundation reduces the base shear with respect to a traditional foundation, and that the optimization procedure based on PI seems to deliver slightly better results than the EDI procedure. Furthermore, the general trend shows that the performance of the Metafoundation increases with the foundation flexibility, as predicted by the optimization results discussed in Section 5. 

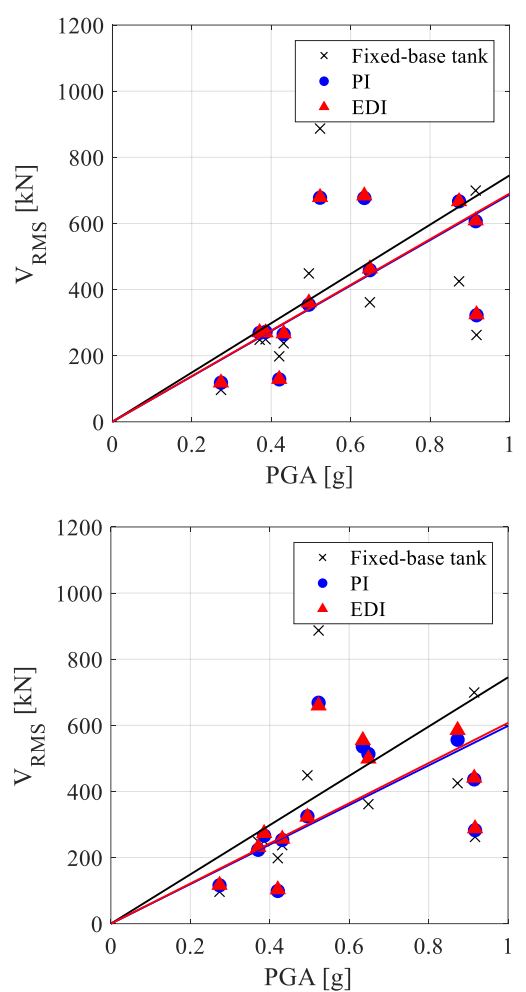

a)
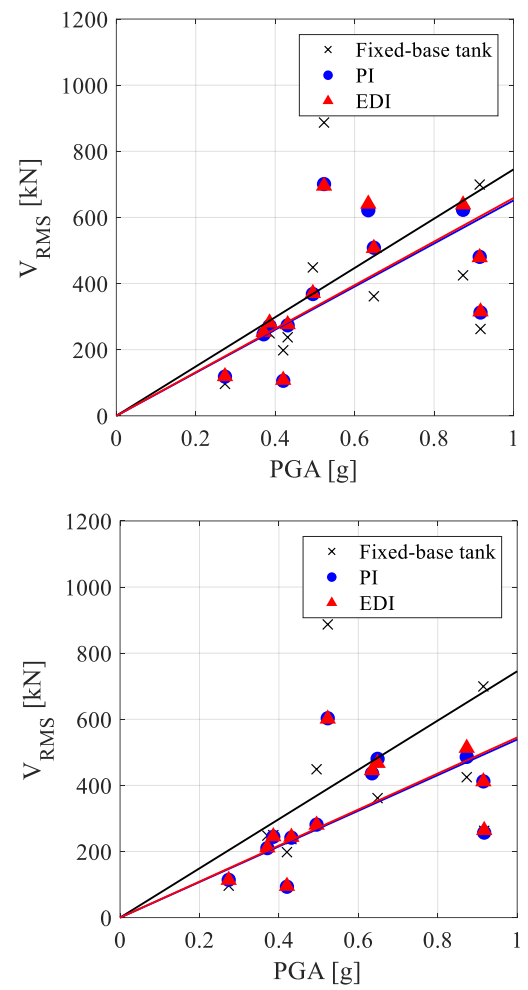

b)

Figure 11 RMS of the base shear of a slender tank vs. PGA of the SSE records: a) L2H3; b) L2H4; c) L1H3; d) L1H4.

Figure 12 shows the reduction of the base shear obtained for every optimized Metafoundation. Here, the black points represent $\alpha$ of (38) obtained for the coupled system subjected to individual seismic records, whereas the red and blue lines display mean values.

It is possible to observe that the $\mathrm{L} 1 \mathrm{H} 3$ foundation increases the base shear although the corresponding linear regression shows a slight reduction, as depicted in Figure 11a. This is because the regression defines a law between the base shear and PGA of the accelerograms, whereas the mean value of parameter $\alpha$ doesn't take this relationship into account. Note that the reduction of the base shear shows a high dispersion due to the variability of the accelerograms. However, it is a simple parameter that highlights the trend of the base shear for the considered Metafoundations.

Furthermore, in order to display the effect of their isolation capability, the foundation typologies are ordered by their $\varepsilon$ value. An average reduction of the base shear between $10 \%$ and $15 \%$ can be achieved with the optimized foundations L1H3 an L1H4. Conversely, poor results are obtained for the two-layered cases due to the increased stiffness of the foundation. These graphs also support the conclusion that the PI procedure provides a slightly better optimized foundation than the EDI procedure. The fundamental difference between these procedures is that the PI evaluates the minimal absolute acceleration of the impulsive mode while the EDI takes into account the energy dissipated by the resonators.

THAs of the coupled foundation-slender tank systems for the Priolo Gargallo soil corresponding to the OBE events are not presented for brevity. It shall be mentioned that they show very similar results as for the SSE events and further underline the functionality of the system. 


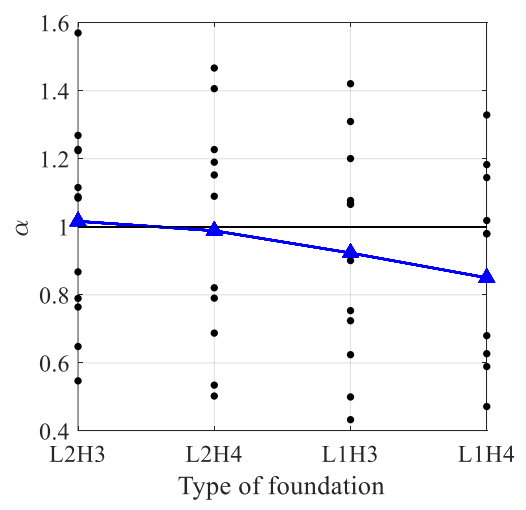

a)

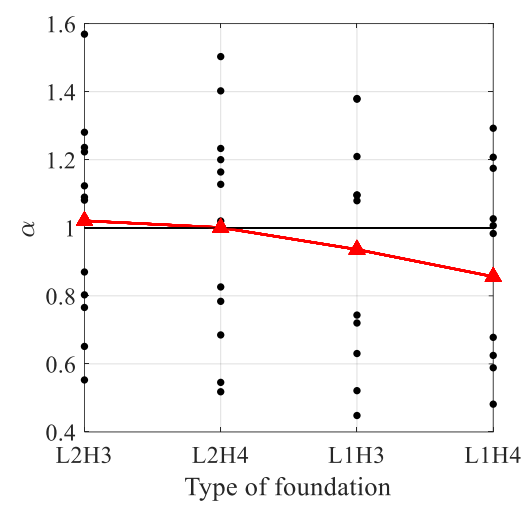

b)

Figure 12 Base shear reduction for a slender tank subjected to SSE events: a) PI optimization; b) EDI optimization.

\subsection{Results for the coupled foundation-broad tank system}

Figure 13 shows the RMS of the base shear of the coupled system foundation-broad tank with the optimal parameters obtained for the Priolo Gargallo soil corresponding to the SSE events. Also in this case, each Metafoundation reduces the base shear with respect to a traditional foundation.

The general trend, shown in Figure 14, highlights the impact of the flexibility on the effectiveness of the Metafoundation systems. Here it can be seen that the best performance, for SSE events, was obtained for the L1H4 foundation system achieving a base shear reduction of up to $30 \%$. When comparing these results to the slender tank analyses, it becomes evident that the Metafoundation has a much greater effect on the broad tank system. Even for the two layered setups the broad tank may experience a demand reduction of about $10 \%-15 \%$. This is caused by the decoupling of the frequencies of the tank from the expected ground motion and further underlines the importance of the superstructure to the performance of the overall system.
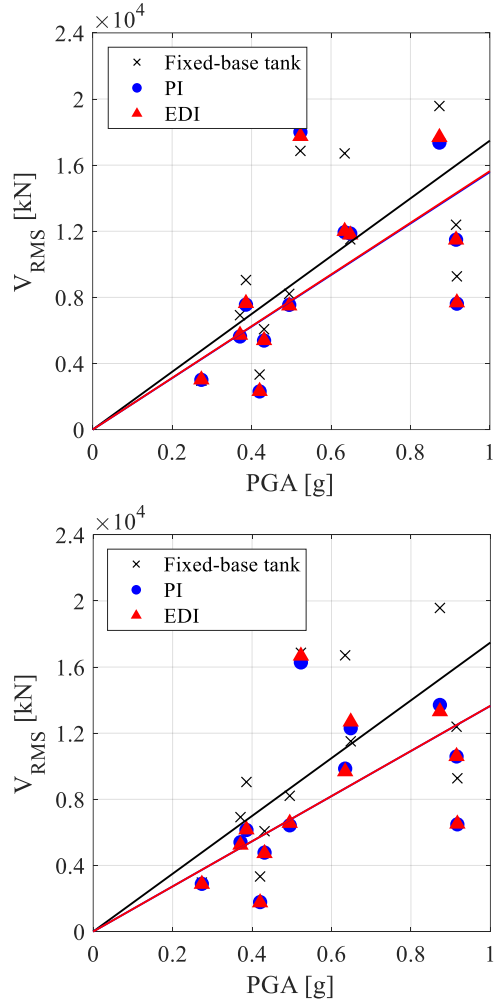

a)
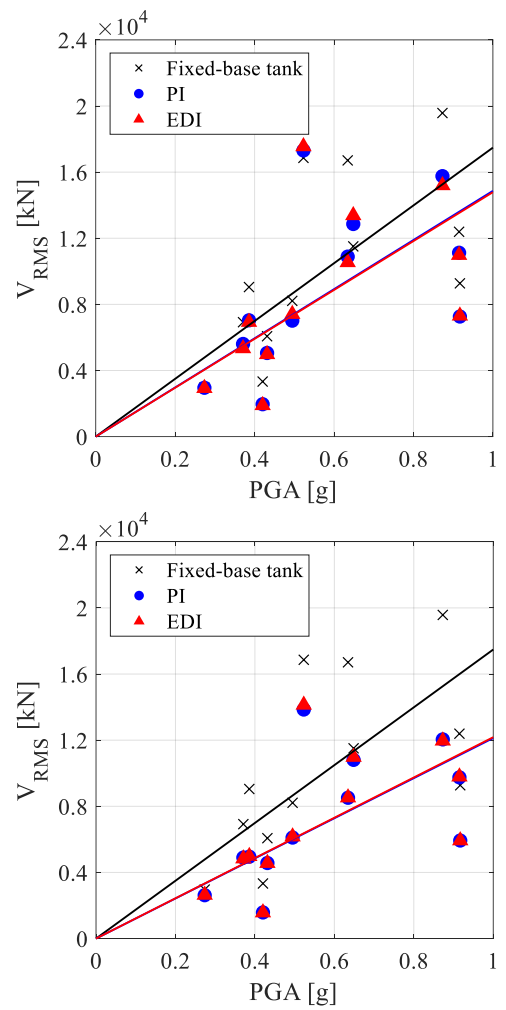

b)

d)

Figure 13 RMS of the base shear of a broad tank vs. PGA of the SSE records: a) L2H3; b) L2H4; c) L1H3;

d) $\mathrm{L1H4}$. 


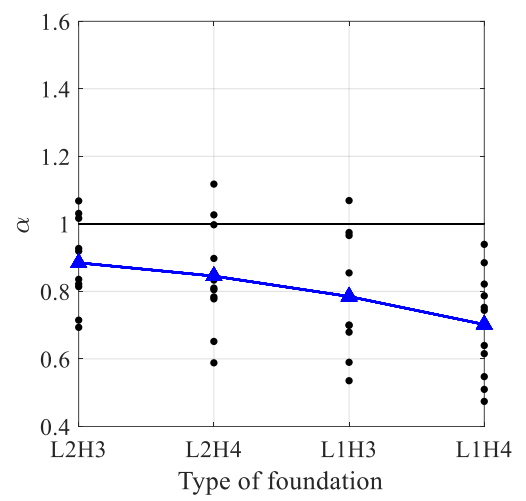

a)

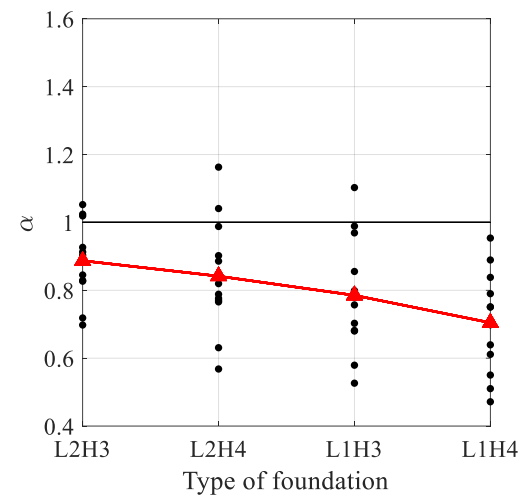

b)

Figure 14 Base shear reduction for a broad tank subjected to SSE events: a) PI optimization; b) EDI optimization.

\section{CONCLUSIONS}

In this article, we presented a foundation based on a metamaterial concept, i.e. the Metafoundation, that has been both designed and optimized. In particular, it exploits the properties of metamaterials and combines them with classical seismic isolation concepts. In order to show that this class of structures can be built under realistic circumstances, the proposed Metafoundation system has been designed according to the Italian standards with excessive conservatism. Note that the construction details are not fully developed; however, in order to address the durability of the system at this early stage, we only use common construction materials and devices such as steel, concrete and wire ropes. Furthermore, the system was designed for a highly vulnerable superstructure, namely fuel storage tanks, and for a very active seismic-prone site. The tuning of this coupled system has been achieved via two optimization algorithms operating in the frequency domain, which are able to account for the superstructure as well as the ground motion spectrum. These algorithms are newly established in the field of mechanical metamaterials, and show that the superstructure has a significant influence on the functionality of the Metafoundation. Additionally, they clearly display the influence of the shear stiffness, and therefore, the isolator-like properties. After optimizing the parameters of the Metafoundation, time history analyses were carried out. Favorable results were obtained for the isolation of a broad fuel storage tank with a base shear reduction of about $30 \%$, while for the slender tank the proposed system seems to be a bit less effective with maximum reduction capabilities of about $15 \%$. These results lay down the basis for future studies and developments of the Metafoundation such as, tuning several resonators to different frequencies, employing more advanced optimization procedures, adding another metamaterial-like concept like negative stiffness elements, or designing the foundation for the attenuation of the vertical component of an earthquake. Overall, the proposed standards-compliant metamaterial-based foundation, if properly optimized, can effectively reduce stresses in broad/slender fuel storage tanks for site-specific seismic hazards.

\section{ACKNOWLEDGMENTS}

This project has received funding from the European Union's Horizon 2020 research and innovation program under the Marie Skłodowska-Curie grant agreement No 721816 for the second author and the SERA grant agreement No. 730900 for the remaining authors. Moreover, the useful discussion with Prof. Ziqi Wang -Earthquake Engineering Research \& Test Center of Guangzhou University - about non stationary stochastic models of seismic records is acknowledged.

\section{REFERENCES}

1. Cruz AM, Steinberg LJ. Emerging Issues for Natech Disaster Risk Management in Europe. Journal of Risk Research 2006, 9(5): 483-501.

2. Nakashima M, Lavan O, Kurata M, Luo Y. Earthquake Engineering Research Needs in Light of Lessons Learned from the 2011 Tohoku Earthquake. Earthquake Engineering and Engineering Vibration 2014; 13: 141-149. 
3. Fabbrocino G, Irevolino I, Orlando F, Salzano E. Quantitative risk analysis of oil storage facilities in seismic areas. Journal of hazardous Materials 2005; 123: 61-69.

4. Kelley JM, Konstantinidis. Mechanics of rubber bearings for seismic and vibration isolation. John Wiley \& Sons 2011.

5. Mokha A, Constantinou C, Reinhorn AM, Zayas VA. Experimental Study of Friction-Pendulum Isolation System. Journal of Structural Engineering 1991; 117(4): 1201-1217.

6. Karimzadeh Naghshineh A, Akyüz U, Caner A. Comparison of fundamental properties of new types of fibermesh-reinforced seismic isolators with conventional isolators. Earthquake Engineering and Structural Dynamics 2014; 43: 301-316.

7. Van Ngo T, Dutta A, Deb SK. Evaluation of horizontal stiffness of fibre-reinforced elastomeric isolators. Earthquake Engineering and Structural Dynamics 2017; 46: 1747-1767.

8. Schellenberg AH, Sarebanha A, Schoettler MJ, Mosqueda G, Benzoni G, Mahin SA. Hybrid. Simulation of Seismic Isolation Systems Applied to an APR-1400 Nuclear Power Plant. PEER Report No. 2015/05 Pacific Earthquake Engineering Research Center. Headquarters at the University of California, Berkeley.

9. Wang P, Casadei F, Shan S, Weaver JC, Bertoldi K. Harnessing buckling to design tunable locally resonant acoustic metamaterials. Physical Review Letters 2014; 113(1): 014301.

10. Finocchio G, Casablanca O, Ricciardi G., Alibrandi U, Garescì F, Chiappini M, Azzerboni B. Seismic metamaterials based on isochronous mechanical oscillators. Applied Physics Letters 2014; 104(19).

11. Aravantinos-Zafiris N, Sigalas MM. Large scale phononic metamaterials for seismic isolation. Journal of Applied Physics 2015; 118(6).

12. Achaoui Y, Ungureanu B, Enoch S, Brûlé S, Guenneau S. Seismic waves damping with arrays of inertial resonators. Extreme Mechanics Letters 2015; 8: 30-37.

13. Shi Z, Cheng Z, Xiang H. Seismic isolation foundations with effective attenuation zones. Soil Dynamics and Earthquake Engineering 2014; 57: 143-151.

14. Cheng ZB, Shi ZF. Composite periodic foundation and its application for seismic isolation. Earthquake Engineering and Structural Dynamics April 2018; 47(4): 925-944.

15. Bao J, Shi ZF, Xiang HJ. Dynamic Responses of a Structure with Periodic Foundations. ASCE Journal of Engineering Mechanics 2012; 138(7): 761-769.

16. La Salandra V, Wenzel M, Bursi OS, Carta G, Movchan AB. Conception of a 3D Metamaterial-Based Foundation for Static and Seismic Protection of Fuel Storage Tanks. Frontiers in Materials 2017.

17. Kim SH, Das MP. Seismic waveguide of metamaterials. Modern Physics Letters B 2012; 26(17).

18. Palermo A, Sebastian Krödel S, Marzani A, Daraio C. Engineered metabarrier as shield from seismic surface waves. Scientific Reports 2016; 6: 39356

19. Huang J, Shi Z. Attenuation zones of periodic pile barriers and its application in vibration reduction for plane waves. Journal of Sound and Vibration 2013; 332(19): 4423-4439.

20. Dertimanis VK, Antoniadis IA, Chatzi EN. Feasibility analysis on the attenuation of strong ground motions using finite periodic lattices of mass-in-mass barriers. Journal of Engineering Mechanics 2016; 142(9).

21. Casablanca O, Ventura G, Garesc F, Azzerboni B, Chiaia B,2 Chiappini M, Finocchio G. Seismic isolation of buildings using composite foundations based on metamaterials. Journal of Applied Physics 2018; 123(17): 174903.

22. Ghosh A, Basu B. Effect of soil interaction on the performance of tuned mass dampers for seismic applications. Journal of Sound and Vibration July 2004; 274(3): 1079-1090.

23. Wang AP, Fung RF, Huang SC, Dynamic analysis of a tall building with a tuned-mass-damper-device subjected to earthquake excitations. Journal of Sound and Vibration 2001; 244 (1): 123-136.

24. Poh'sie GH, Chisari C, Rinaldin G, Amadio C, Fragiacomo M. Optimal design of tuned mass dampers for a multistorey cross laminated timber building against seismic loads. Earthquake Engineering and Structural Dynamics 2016; 45(12): 1977-1995. 
25. Chowdhury AH, Iwuchukwu MD. The past and future of seismic effectiveness of tuned mass dampers. Proceedings of the Second International Symposium on Structural Control, University of Waterloo, Ontario, Canada, July 15-17, 1985.

26. Yamaguchi H, Harnpornchai N. Fundamental characteristics of Multiple Tuned Mass Dampers for suppressing harmonically forced oscillations. Earthquake Engineering and Structural Dynamics 1993; 22(1): 51-62.

27. Abé M, Fujino Y. Dynamic characterization of multiple tuned mass dampers and some design formulas. Earthquake Engineering and Structural Dynamics 1994; 23(8): 813-835.

28. Igusa T, Xu K. Vibration control using multiple tuned mass dampers. Journal of Sound and Vibration 1994; 175(4): 491-503.

29. Li C. Performance of multiple tuned mass dampers for attenuating undesirable oscillations of structures under the ground acceleration. Earthquake Engineering and Structural Dynamics 2000; 29(9): 1405-1421

30. Li HN, Ni XL. Optimization of non-uniformly distributed multiple tuned mass damper. Journal of Sound and Vibration 2007. 308(1-2): 80-97.

31. Joshi AS, Jangid RS. Optimum parameters of multiple tuned mass dampers for base-excited damped systems. Journal of Sound and Vibration 1997; 202(5): 657-667.

32. Miguel FFM, Lopez RH, Miguel LFF, Torii AJ. A novel approach to the optimum design of MTMDs under seismic excitations. Structural Control and Health Monitoring November 2016; 23(11): 1290-1313.

33. Hoang N, Warnitchai P. Design of multiple tuned mass dampers by using a numerical optimizer. Earthquake Engineering and Structural Dynamics February 2005; 34(2): 125-144.

34. Reggio A, De Angelis M. Optimal energy-based seismic design of non-conventional Tuned Mass Damper (TMD) implemented via inter-story isolation. Earthquake Engineering and Structural Dynamics 2015; 44:1623-1642.

35. CS.LL.PP. DM 14 Gennaio, Norme tecniche per le costruzioni. Gazzetta Ufficiale della Repubblica Italiana; 2008.

36. Alessandri S, Giannini R, Paolacci F, Malena M. Seismic retrofitting of an HV circuit breaker using base isolation with wire ropes. Part 1: Preliminary tests and analyses. Engineering Structures 2015; 98: 251-262.

37. Malhotra PK, Wenk T, Wieland M. Simple procedure for seismic analysis of liquid-storage tanks. Journal of the International Association for Bridge and Structural Engineering August 2000; 10(3): 197-201.

38. NEA/CSNI/R(2007)17, 2008. Differences in approach between nuclear and conventional seismic standards with regard to hazard definition. In: CSNI Integrity and Ageing Working Group, Nuclear Energy Agency Committee on the Safety of Nuclear Installations.

39. Baker JW, Cornell AC. A vector-valued ground motion intensity measure consisting of spectral acceleration and epsilon. Earthquake Engineering and Structural Dynamics 2005, 34(10): 1193-1217.

40. Caputo AC, Paolacci F, Bursi OS, Giannini R. Problems and perspectives in seismic Quantitative Risk Analysis of chemical process plants. Journal of Pressure Vessel Technology. Under review

41. Phani AS, Woodhouse J, Fleck NA. Wave propagation in two-dimensional periodic lattices. Journal of the Acoustical Society of America 2006; 119(4): 1995-2005.

42. Kelly J. Base isolation: linear theory and design. Earthquake Spectra 1990; 6(2):223-244.Huang HH, Sun CT, Huang GL.

43. On the negative effective mass density in acoustic metamaterials. International Journal of Engineering Science April 2009; 47(4): 610-617

44. Feng MQ, Mita A. Vibration control of tall buildings using mega subconfiguration. Journal of Engineering Mechanics October 1995; 121(10): 1082-1088.

45. Kanai K. Semiempirical Formula for the Seismic Characteristics of the Ground. Bulletin of the Earthquake Research Institute 1957; 35(1957): 309-324

46. Clough RW, Penzien J. 1975. Dynamics of Structures. McGraw-Hill 1975, New York.

47. Palazzo B, Petti L. Stochastic response comparison between base isolated and fixed-base structures. Earthquake Spectra February 1997; 13(1): 77-96. 


\section{APPENDIX}

In this Appendix, we show how to estimate the time modulating function of the power spectral density (PSD) function for time modulated zero-mean Gaussian processes that represent the seismic records introduced in Subsection 2.4. At the outset, the PSD function can be written as,

$S(\omega, t)=\phi^{2}(t) S_{s t}(\omega)$

in which $\phi(\mathrm{t}), \phi(\mathrm{t}) \leq 1$, is the time modulating function and $S_{s t}(\omega)$ is the stationary PSD function. With a set of N seismic records denoted with $\tilde{\ddot{u}}_{s}^{(i)}(t)$ where $i=1,2, \ldots, \mathrm{N}$, we can define an estimate $\tilde{\phi}(t)$ of $\phi(\mathrm{t})$ as,

$\tilde{\phi}(t)=\frac{\tilde{\sigma}(t)}{\max [\tilde{\sigma}(t) \mid t \in[0, T]}$

where $\tilde{\sigma}(t)$ is the estimate of the standard deviation of the recorded signals and $\mathrm{T}$ is the duration of the process. By means this time modulating function $\tilde{\phi}(t)$, to a set of non-stationary signals $\ddot{u}_{g, s t}{ }^{(i)}(t)$, a set of pseudo stationary signals $\tilde{u}_{g, s t}{ }^{(i)}(t)$ can be evaluated as,

$\tilde{u}_{g, s t}^{(i)}(t)=\frac{\tilde{\ddot{u}}_{g}^{(i)}(t)}{\tilde{\phi}(t)}$

With the Fourier transform of $u_{g, s t}^{(i)}(t)$, we can discretize a finite set of normal random variables realized as stationary Gaussian processes as,

$\ddot{u}_{g, s t}(t) \cong \sum_{p=1}^{M / 2}\left[A_{p} \cos \left(\omega_{p} t\right)+B_{p} \sin \left(\omega_{p} t\right)\right]$

where $\omega_{\mathrm{p}}$ is the sampled frequency with frequency increment $\Delta \omega=2 \pi / T$, and $M$ being the total amount of time steps of each signal. $A_{p}$ and $B_{p}$ are zero mean Gaussian random variables, the so called Fourier coefficients, and can be evaluated as,

$$
\begin{aligned}
& A_{p}{ }^{(i)}=\frac{2}{M} \sum_{k=1}^{\bar{M}}\left[\tilde{\ddot{u}}_{g, s t}^{(i)}\left(t_{k}\right) \cos \left(\omega_{p} t_{k}\right)\right] \\
& B_{p}{ }^{(i)}=\frac{2}{M} \sum_{k=1}^{\bar{M}}\left[\tilde{\ddot{u}}_{g, s t}^{(i)}\left(t_{k}\right) \sin \left(\omega_{p} t_{k}\right)\right]
\end{aligned}
$$

Since the Fourier coefficients are uncorrelated for different frequencies, i.e. $\mathrm{E}\left[A_{p} A_{q}\right]=\mathrm{E}\left[B_{p} B_{q}\right]=\mathrm{E}\left[A_{p} B_{q}\right]=0$, for $\mathrm{p} \neq \mathrm{q}$, we can find,

$$
\mathrm{E}\left[A_{p} A_{p}\right]=\mathrm{E}\left[B_{p} B_{p}\right]=2 S_{s t}\left(\omega_{p}\right) \Delta \omega
$$

$\mathrm{E}\left[A_{p} B_{p}\right]=0$

Finally, using (A.5) and (A.6), an estimate of the stationary PSD function $\tilde{S}_{s t}\left(\omega_{p}\right)$ of the records $\ddot{u}_{g, s t}^{(i)}(t)$ can be estimate as, 


$$
\tilde{S}_{s t}\left(\omega_{p}\right)=\frac{1}{N \bar{M}^{2} \Delta \omega} \sum_{i=1}^{N}\left|\sum_{k=1}^{\bar{M}}\left[\tilde{u}_{g, s t}^{(i)}\left(t_{k}\right) e^{i \omega p t k}\right]\right|^{2}
$$

